\title{
The Prospects of Future Production: An Arena for Emerging New Strategies and Policies of Manufacturing-The Household Appliance Industry’s Review
}

\author{
Ahmad Reza Ghasemi ${ }^{1}$, Arshia Taimouri ${ }^{2} \&$ Alireza Sayadi $^{3}$ \\ ${ }^{1}$ University of Tehran, Farabi Campus, Qom, Iran \\ ${ }^{2}$ Industrial Management, University of Ershad-Damavand, Tehran, Iran \\ ${ }^{3}$ Financial Management, University of Kar, Zanjan, Iran \\ Correspondence: Ahmad Reza Ghasemi, University of Tehran, Farabi Campus, Qom, Iran. E-mail: \\ editor.hamyari@gmail.com
}

Received: November 23, 2016

Accepted: April 30, 2017

Online Published: May 17, 2017

doi:10.5539/ijbm.v12n6p203

URL: https://doi.org/10.5539/ijbm.v12n6p203

\begin{abstract}
Nowadays, manufacturing is one of the most important indicators of human societies development, and receiving an outstanding feedback from manufacturing sector, causes economic strength improvement of a country. Researching about operations management stretches back to long time ago and always human beings have attempted to codify their activities in order to gain their targets. Given rapid and fundamental changes in organizations and human societies, undoubtedly in the near future we will experience a new era of industrial manufacturing. Regarding to this subject, governments and organizations, by adopting accurate manufacturing strategies and policies should prepare themselves for presenting in the new area. In this article, initially we investigate major problems and issues related to industrial manufacturing that managers and policy makers deal with. Then future manufacturing characteristics are mentioned and finally the ways of making manufacturing policies and appropriate strategies are reviewed.
\end{abstract}

Moreover, we have investigated the status of household appliance industry in Iran, by interviewing with experts in this industry. Eventually for improving the status some applicable policies and strategies are proposed.

Keywords: policies of manufacturing, Strategy, Industry

\section{Introduction}

Manufacturing sector in recent years has been experiencing major changes, and we expect more changes in this regard in the future (Joel Segal et al., 2013). It seems new and exciting era of global production ahead. The development cycle of new technologies and continuous technological innovations has led to the creation of new markets and the rate of changes has increased the demand of production units. The expansion of international trade and global competition is getting tougher in the highly competitive global markets that are only successful producers and superior quality products to market quickly and properly provide the required services to customers. In other words, the global products and services are only those products which can compete in the market. Essentially, all these changes and opportunities will occur, thus resulting in a global environment of increasing complexity, uncertainty and risk in consequence (Richard Dobbs et al, 2012).

With the changes expected to occur in production, without any doubt, there should also be developed appropriate strategies Companies that continue with the same vision of "business as usual" will continue to be at risk. Sure, other manufacturers will not be able to copy and run through the old strategies to succeed in the new conditions, but they need to develop a proper understanding of the world and plan operational strategies. The policy makers of production field should adjust and coordinate their attitudes and expectations and consider production not as a source of employment in traditional manufacturing production, but as a fundamental driving innovation, productivity, and competitiveness look (Richard Dobbs et al., 2012). The impact of government policies on a number of drivers of competitiveness, such as trade, monetary and financial issues, tax, legal systems, infrastructure, education, labor market, science, technology can be very important. While increasing the strategic use of public policy development, the importance of cooperation between policymakers and business leaders in 
order to create win - win will be increasingly important. (Report of the World Economic Forum, 2013)

\section{Literature Review}

The term manufacture is taken from two words, Manu, that means manual and Facture, which means making. The transformation of raw materials into manufactured goods is the primary meaning of production. The trigger point of manufacturing stretches back to the industrial revolution, when the larger scale of production was required (Jovane et al., 2008).From that time on, manufacturing concept has changed significantly due to the development of technology, processes and other crucial factors. In addition, nowadays an overwhelming majority of experts and authors strongly contend that during the past decades because of globalization new economies have taken the responsibility of considerable proportion of manufacturing capacity and accordingly substantial new markets and new competitors emerged. This process has caused contemporary and dramatic changes to the concept of manufacturing.( Peter Bosch et al., 2012). New definitions have been submitted for manufacturing, such as "Application of knowledge and technical expertise leading to the creation of products, production processes and related services that have potential for sustainable growth and to provide high economic value to the manufacturing sector, Including research and development activities that take place on the one hand and on the other hand is recycling products (Technology Strategy Board, 2012)".

The term strategy is adopted from the Greek word "strategos "means the generals" art and has been used in military science. Strategy in its present form, is one of the achievements of the World War II .In the early 1960s, the department of defense of the U.S.A established the foundations of strategic planning And two years later the concept was introduced to the world of academia and in the 1990s a new era of strategic approaches by experts such as Henry Mintzberg and Garry Hamel began .By using various types of strategies, organizations can achieve their long term goals.

The policy is defined as a set of adopted fundamental activities, targeted by the government, various groups, specific businesses and individuals. Besides, the policy-making is defined as a process by which governments interpret their political landscape through a variety of programs and operations to achieve meaningful results. There are several types, such as rules and regulations, non-interference and so forth on (Nigel Hamilton et al, 2012). Mark Walport et al (2013) in an article named future production (a new realm of opportunities and challenges for the UK) production characteristics in the next 50 years were examined and the necessary policies needed to meet the future field development and production for the United Kingdom proposal has done. Their future production to be faster, more responsive, more closely with the customer, stable, and have predicted dependent on skilled labor and had formulated a policy in the following three categories: 1-Using the new forms of knowledge and acumen to achieve smarter insights on the manufacturing sector and in which areas the value should be created. 2-Targeted approaches taken to support producers based on systematic understanding of science, technology, innovation and industrial policies 3-Adapting and creating new, innovative and organizational capabilities for the future.

In addition Mr. Joel Segal et al (2013) by reviewing the challenges facing manufacturing in the future, have determined required strategies for companies in order to defeat them, so that includes three principles: innovation, global presence and integrating operational and financial plans. Mr. Richard Dobbs et al (2012) in a report entitled Building the Future (arena for innovation and global growth) by analyzing the current status of production in the global economy and problems in this area as well as the emerging field of producing side effects such as changes in demand, innovation in materials first, processes, information technology, and manufacturing operations, and so on strategies and policies need to be applied to all nations and governments have developed.

\section{Methodology}

The current research is considered as an applied research and based on how to achieve required data is considered as a descriptive and survey one. The main industry in this research is Household appliances industry. This industry is one of the fields of industrial development accelerator. Data collection was done through interviews with experts and scholars in this industry. Mr. Shanehsaz from the Association of Household appliances industry, Mr. Biglarpour from the Ministry of Industry, Mine and Trade, and Mr. TahanPour president of the Association of household appliances were our main interviewees, who were interviewed on various issues such as: the current status of the Household appliances industry in Iran(strengths and weaknesses), the policies of decision maker organizations, the strategies which manufacturers are applying and the outlook of this industry. 


\section{Research Purposes}

1) Identifying the challenges and issues currently facing production and producers

2) Identifying the characteristics of future production

3) The new production strategies and policies to deal with new areas of production in the future

4) Checking the status of the Household appliances industry of Iran and offering necessary policies in order to develop this industry.

\subsection{The Main Challenges Facing Manufacturing and Producers}

1-The non-fixed raw materials

The main raw materials are scarce resources and being and non-being product markets means that there is a serious threat to profits. Factories and companies through innovation (replacement of other raw materials) and changing in operational models will respond.

\section{2-Success in Emerging Markets}

Most organizations have shown their presence in emerging markets. The main problems faced are: cultural differences, weakness of fiscal policies, poor infrastructure of destination countries, nurturing local talent in dealing with import and so on.

\section{3-Competitive threats}

Newcomers of emerging markets and more unity and cooperation among companies are the main reasons of increases in competition, importance of pricing and decrease of profit margins. Factories and companies can, through innovation in product or service or to maximize performance and improve business processes react and compete.

\section{4- The increasing complexity}

Most of the pressures on businesses are in fact a combination of structural complexity and making difficult decisions. Legislative changes also affect periodically on key investment decisions. The companies that are agile and cautious will deal with global competition perfectly.

\section{5- The struggle for the possession of the elite}

Decisions about where and how we manage the business depends on it where we can find talented people. International companies will need to identify competent leaders who have operational and management experience. (Joel Segal et al., 2013)

\subsection{The Key Features of Future Production}

1) Faster, more responsive and closer links with customers

2) The existence of new market opportunities

3) Stability

4) Greater reliance on professional staff

\subsection{Golden Tips for Strategy Codification in the Future}

As companies and industries are looking for ways to grow and expand resources and are trying to be one step ahead of the competition, it is necessary to remove unnecessary complexity and create flexible operating model to achieve more Agility. Trade issues and business managers should also be in line with new strategic objectives and execution models which are chosen. Some basic tips that manufacturing leaders need to consider strategies with respect to today's conditions include:

\section{1) Innovation}

Investing and planning for the future in today's global market requires that organizations create innovations and be able to commercialize their innovations more efficiently. Production management, technology engineering and skills are terms that are currently becoming essential in the world of production. Models which companies choose to rely on innovations, processes and technology that meet and maintain optimal investments themselves are all aspects of successful innovation. Companies and different organizations often try to communicate with customers through understanding properly their requirements. The main goal in this regard is to deal with competitive threats through creating a higher level of customer loyalty. However, this situation provides the stage for the emergence of new innovations. Another important aspect is the innovative use of new technologies. 
Intelligent software, substitution of raw materials, automation, robots, new processes (such as 3D printing) have transformed traditional production. New innovations along with cutting-edge technologies provide platform to process complex products with minimal interference and a massive investment in machinery and equipment to be manufactured.

\section{2) Sufficient attention to the global processes}

Globalization in many factories and manufacturing companies with complex range of machinery research and development centers, distribution and after-sales service is obtained. Due to the complex supply chain, many organizations over the issue of the balance between domestic production and supply chain execution in line with global management and decision-making are confused.

\section{3) Creating agility in the organization}

For detailed response to the opportunities and challenges that will be created, manufacturers need to move faster and process changes and predict trends. Production in the future, companies must be flexible and fast, and also have the ability to heal after injuries and be committed to strategies to achieve long-term opportunities.

\subsection{Household Appliance Industry}

Household appliance industry is one of the fields of industrial development accelerator. An industry with various applications, so that besides extensive household usages plays a pivotal role in office and commercial sectors along with markets around the world. In fact, home appliance industry creates added value for different industries, such as Steel, Petrochemical and Copper. Nowadays, producers of home appliances due to the changes of situation and effective factors are experiencing a sensitive and complicated phase.

\subsection{The Current Situation of Household Appliance Industry in Iran}

Home appliance industry has a long history and it has been nearly more than 6 decades available in Iran. In recent decades, considerable amounts of needs have been supplied by domestic production. This important industry, with high investment volume and dramatic history is one of the significant industries. In addition to direct employment, a large number also in the service, distribution, maintenance and so on as the indirect employment are active. Currently, 20 major production units with a variety of products and hundreds of factories, large and small companies and workshops around the country are engaged in the production and supply of products. These production units along with related services, such as after-sales services and qualified service shops have employed a huge number of labor force.

\subsection{Exporting Household appliances}

Household appliances export have fluctuated over the last ten years and the process according to the economic conditions and other factors affecting the region and target countries in global trade is variable. At the end of Year 2010 and Year 2011 because of increase in production costs due to the new economic policy in the country and international constraints, competition in global markets has become

Table 1. Iran's export in the past several years (Household Appliances)

\begin{tabular}{lll}
\hline & Million Dollars & Targeted Countries \\
\hline 2001 & 17 & AZERBAIJAN-IRAQ-UAE-GEORGIA-ARMENIA \\
2002 & 35 & IRAQ-UAE-ARMENIA-AZERBAIJAN-TAJIKISTAN \\
2003 & 83 & IRAQ-ARMENIA-AZERBAIJAN-AFGHANISTAN-UAE \\
2004 & 59 & IRAQ-ARMENIA-TAJIKISTAN-UAE-AZERBAIJAN \\
2005 & 99 & IRAQ-ARMENIA-ALGERIA-AZERBAIJAN-AFGHANISTAN \\
2006 & 138 & IRAQ-ARMENIA-UAE-AZERBAIJAN-TAJIKISTAN \\
2007 & 105 & IRAQ-AFGHANISTAN-ARMENIA-AZERBAIJAN-SUDAN \\
2008 & 155 & IRAQ-AFGHANISTAN-ARMENIA-TAJIKISTAN-AZERBAIJAN \\
2009 & 210 & IRAQ-AFGHANISTAN-ALGERIA-SYRIA-ITALY \\
2010 & 283 & IRAQ-AFGHANISTAN-ITALY-SYRIA-ALGERIA \\
2011 & 249 & IRAQ-AFGHANISTAN-ITALY-SUDAN-UAE \\
\hline
\end{tabular}




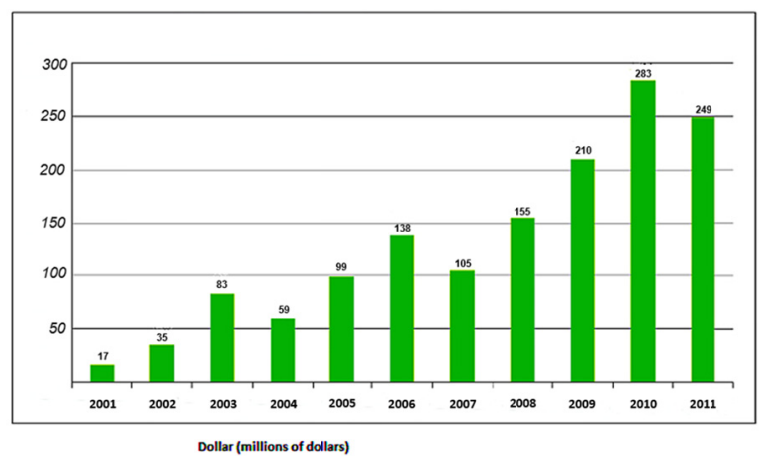

Figure 1. Iran's export in the past several years (Household Appliances)

According to the table1 and figure1, it is important to note two things here: 1) By reviewing the amount of export in recent years, it is clear that what we are going to take is a changing export growth rate and this rate does not experience a permanent ascending trend, which demonstrates that household appliance industry in Iran is dealing with different types of issues and problems. 2) We see that a large share of our exports is to neighboring countries carried out the result of our inability Household appliance industry to compete with European and American countries which are leaders in this regard.

\subsection{Importing Household Appliances}

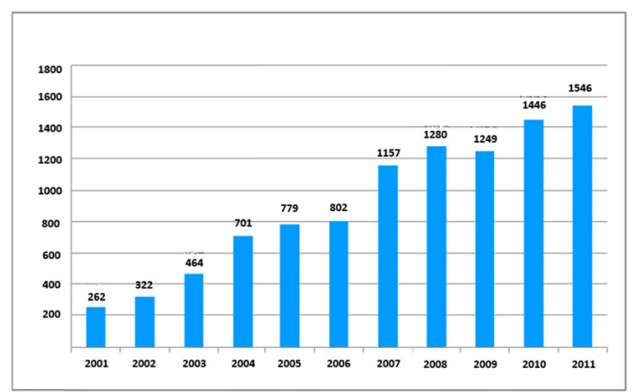

Figure 2. Iran's import in the past several years (Household Appliances)

Table 2. Iran's import in the past several years (Household Appliances)

\begin{tabular}{lll}
\hline & Million Dollars & Targeted Countries \\
\hline 2001 & 262 & UAE-CHINA-ITALY-SOUTH KOREA-GERMANY \\
2002 & 322 & UAE-GERMANY-SOUTH KOREA-ITALY-CHINA \\
2003 & 464 & UAE-ITALY-CHINA-FRANCE-GERMANY \\
2004 & 701 & UAE-SOUTH KOREA-CHINA-CANADA-GERMANY \\
2005 & 779 & UAE-SOUTH KOREA-CHINA-CANADA-GERMANY \\
2006 & 802 & UAE-CHINA-ITALY-GERMANY-SOUTH KOREA \\
2007 & 1157 & UAE-CHINA-GERMANY-ITALY-TURKEY \\
2008 & 1280 & UAE-CHINA-ITALY-TURKEY-BELGIUM \\
2009 & 1249 & UAE-SOUTH KOREA-CHINA-TURKEY-GERMANY \\
2010 & 1446 & UAE-CHINA-TURKEY-SOUTH KOREA-GERMANY \\
2011 & 1546 & UAE-CHINA-TURKEY-SOUTH KOREA-GERMANY \\
\hline
\end{tabular}

Unfortunately, the country is also experiencing difficulties in importing. In recent years the issue of sanctions has led to a greater share of our imports only from countries like China, Turkey, South Korea and the United Arabic Emirates take place. 


\subsection{Some of the Problems and Obstacles of the Household Appliance Industry in the Country}

With the current trend of exports and the influx of foreign goods into the country and also by considering elite's standpoints, it is obvious that the domestic appliance industry, has been experiencing serious problems and if the experts and authorities do not adopt proper solution for this industry, in the next few years it will certainly be a failed industry. In the following, main problems of this industry will be discussed.

\subsection{Raw Materials Procurement}

One of the obstacles that nearly all production units have been involved with. Steel, petrochemical, copper and aluminum are the main raw materials used in this industry and producers in Iran do not have an appropriate situation through providing raw materials, which could be investigated in two aspects. First of all, the raw materials do not have a stable price and it is not possible to predict their prices in the next two or three months. Second of all, timely delivery should be taken in to account. Stable raw material costs are directly related to the stabilization of the exchange rate. In fact, the currency management is one of the tools that will allow producers to plan for the future, so that not only would they be able to import their raw materials, but they can export their products.

\subsection{Lack of Liquidity}

Thinking about highly valuable collateral to submit a bank in order to take out a mortgage, is one of the most important problems facing producers and industrial units. Lack of liquidity causes the industrial units do not plan for their future activities.

\subsection{Excessive Import}

As previously mentioned, the issue of excessive import has hampered the growth of household appliance industry. Excessive import has deteriorated the motivation among Iranian producers. A major weakness seen in some imported goods to the country, is the low quality of these goods and in order to support domestic production the government should prevent the entry of such goods into the country and also it is necessary to import foreign products on the basis of a quality system.

\subsection{Inflationary Effects of Increasing Energy Prices}

This case is one of the issues that is involved in household appliance industry. In production units of household appliances fuel consumption is high. It is evident that, due to the increased energy prices, changes in production processes and the price of products would be observed. The solution to this problem is to optimize energy consumption in industrial plants, which must pay special attention to it in written policies.

\subsection{Lack of Proper Communication between Industry and Academia}

It is one of the shortcomings that household appliance industry of country needs it urgently. Today, with the advent of the new era of high value production and research and development in manufacturing processes, it is necessary to create a broad and increasingly productive relationship between industry and university scientific attention.

\subsection{Lack of Sufficient Attention to Branding}

A seemingly small problem, but essential is the number of household appliance producers in the country. In fact, most of these production units produce similar products or with their minimum capacity. These shortcomings and problems do not allow us to compete globally and mostly rely on domestic competition.

\subsection{Capacities and Capabilities in the Country}

1-There are young, active and talented labor force 2-Taking the advantage of specialists in the fields of electronics, mechanical engineering and so forth 3-High added value of household appliance industry 4-Household appliance industry is considered as one of the rings complete the production of value-added upstream industries such as copper, steel and petrochemicals

\section{Conclusions}

By examining trends and clarifying characteristics of production in the future as being faster, more flexible, closer relationship with the customer, facing the emerging markets, more stable, more need for skilled labor, undoubtedly we will observe the new era of industrial production within next few years. Generally alarm has sounded for manufacturers that if they cannot adapt to environmental changes and still want to continue their same old procedures, without any doubt in the next few years, due to the inability to compete with other rivals, will be suffered dramatically and in the end inevitably they will be forced to leave the field of production. Most managers of the industrial sector by having a glance to innovation, global processes, challenges and legal and tax 
barriers, looking for strategies, so that they can have sustainable growth and remain competitive. In fact, the managers will experience the new changes in production management in a global environment, the advent of technological advances, as well as increased competition and changes in customer demand. The government can also by codifying vital policies in various areas, such as financial monetary affairs, taxation, regulation, infrastructure, education, technology, education help manufacturers to face the new stage of production. But in relation to the outlook of household appliance industry, we can mention that if the current sanctions were removed a good outlook for the household appliance industry could be considered. Our main competitor in the region is Turkey that with a fundamental planning we can defeat this country. Accordingly, proposed policies and programs for the industry of household appliances are: 1) Attempting to use energy more efficiently in this industry 2) Taking the issue of branding in to high consideration and expanding brand from the design stage to production and services before, during and after the sale in order to develop the industry in the region and globally. 3) Expansion of ties between universities and the industry 4) Carrying out necessary investments in order to attract cutting-edge technologies and improve existing technologies and consequently increase R \& D activities 5) Preventing excessive import of foreign shoddy goods 6) Taking the necessary measures to improve the quality of products in collaboration with the National Institute of Standards and Industrial Research of Iran 7) Attempting to provide after sales service perfectly and develop relevant standards 8) There are great deal of raw material resources in the country, so that by an effective management we can supply the needs of our country 9) Attempting to absorb capitals in the private sector 10) Controlling the banking systems and the process of providing banking facilities more accurately. 11) Attempting to stabilize the exchange rate.

It should be noted at the end that if marginal issues that have preoccupied the industry, such as credit, raw material supply, inadequate attention to the protection of domestic production, more efficient activities will disappear and the good future for this industry will be predicted.

\subsection{Recommendations for Future Research}

1) Codifying policies and strategies in other part of the country's manufacturing industry (for example: automotive industry) 2) Addressing future production characteristics (such as agile manufacturing) and submitting operational programs along with solutions to businesses and manufacturing companies to achieve these characteristics.

\section{References}

Amin, F. (1392). electrical and electronic equipment supply chain strategy University of Beheshti publications. Tehran.

Hassan, M. (2012). Codifying and prioritizing strategies by comparing the Fuzzy approach and QSPM. Journal of New Market Research, 3, 154-135.

Household Appliance Industry Association of Iran. (2014). Statute of Household Appliance Industry Association of Iran.

Joel, S. (2012). Preparing for growth - Manufacturers adopt new strategies for growth and competitive edge. PWC (Industrial Manufacturing Team).

John, M. (2013). Manufacturing for growth strategies for driving growth and employment. A World Economic Forum Report.

Jovane, F. (2008). The incoming global technological and industrial revolution towards competitive sustainable manufacturing. Journal of Manufacturing Technology, 57, 641-659.

Mark, W. (2013). The future of manufacturing-A new era of opportunity and challenges for the UK. Government Office for Science.

Maryam, T. (2012). The household appliance industry, A report from Deputy of import and export of goods.

Mckinsey. (2012). Manufacturing the future -the next era of global growth and innovation. Mckinsey Global Institute.

Nikoukar. (2009). The pattern of consumer behavior and online marketing strategies for household appliances of Iran. Journal of Business Management, 2, 150-135.

Peter, B. (2012). The future of manufacturing opportunities to drive economic growth. A World Economic Forum Report in collaboration with Deloitte Touche Tohmatsu Limited.

Richard, H. (2013). Additive manufacturing. EPSRC Centre for Innovative Manufacturing.

Safa'I. (1391). Fuzzy MCDM approach combination of techniques to prioritize strategies to achieve world class 
manufacturing (Case study: Khuzestan Steel Industry). operations research and its applications, II, 88-99.

\section{Copyrights}

Copyright for this article is retained by the author(s), with first publication rights granted to the journal.

This is an open-access article distributed under the terms and conditions of the Creative Commons Attribution license (http://creativecommons.org/licenses/by/4.0/). 